\title{
Visual Representations of Christianity in Christian Music Videos
}

\author{
ANDREAS HÄGER \\ Åbo Akademi University
}

\begin{abstract}
This article discusses Christian rock videos. Videos from a collection entitled Wow Hits 2002: the year's top Christian music videos are used as examples. The title of the collection declares that the videos are "Christian", and the question asked in the article is how this quality may be seen in the videos. How may the videos be seen as visual representations of Christianity? Using a semiotic framework, two possible types of such representations of Christianity in the videos are discussed. These are references to traditional Christian imagery; and the style and appearance of the artists.
\end{abstract}

This article discusses Christian rock videos as an example of the interaction between religion and popular culture. The genre of "contemporary Christian music", or Christian rock, by being rock music as well as an expression of Christianity, stands with one foot in institutional (often evangelical) Christianity and the other in the secular commercial music industry. This article studies how this ambiguous position is manifested in Christian rock videos. Examples will be taken from the Christian hit video collection Wow hits 2002: the year's top Christian music videos. 
The research context for the article is constituted by two overlapping fields of research: sociology of religion and the study of religion and popular culture. The view here is that these fields are connected, as the relation between religion and popular culture is understood as an example of the overarching topic of the sociology of religion: the role of religion in contemporary society. The study of Christian rock, and its expression in music videos, is therefore approached here as part of the sociological study of the place of religion in contemporary society.

The study of religion and popular culture is here viewed as part of sociology of religion, as the discussion on religion and popular culture constitutes a discussion of the place of religion in contemporary society. When it comes specifically to Christian rock, I think one important sociological perspective is to discuss it as part of the attempts of institutional Christianity to deal with modern society. Taking as a starting point Berger's (1967) discussion on the two possible strategies for religion in modern society, to accommodate or to resist, one could say that Christian rock is accommodating by using a contemporary form, but resisting by producing their own version of it. Christian rock is thus an arena for negotiation of the boundary between "Christian" and "secular", and the Christian music videos take part in this negotiation especially in the visual aspects of the videos.

Although the field of research in religion and popular culture is not large, there are some previous studies of Christian rock, among sociological studies most notably Howard \& Streck (1999). Some studies of Christian music videos have also been conducted (Reid \& Dominick 1994; Gow 1999). The main result of these studies, and a result that at least partly corresponds with the analysis here, is that the similarities between Christian music videos and videos of the secular mainstream are greater than the differences.

After these introductory remarks, the article continues with a brief contextual discussion of the phenomenon of Christian rock. A few words on the material itself and the problems surrounding the analysis of such material precede the main part of the article, which is a discussion of the videos themselves. 


\section{Christian Rock}

Different forms of cultural expression have always been essential to the practice of various religious traditions. The use of music within Christianity is one example of this. Religious aesthetic expressions are often quite fixed and stable over time, as the same - or at least what is perceived as the same - expressions are used today as were used centuries ago.

But there are also examples of renewal and change in the forms that are used, and Christian rock, or "contemporary Christian music" (the terms are here understood as synonymous), is an obvious example of this. Christian rock attempts to be a "language in our time" (Lawhead 1982) ${ }^{1}$, and does not aim to use the same musical expressions as Christianity has used traditionally, but rather to appropriate the forms of contemporary music. This appropriation includes the production of Christian counterparts to different styles - Christian hard rock, Christian rap, etc. - and the use of different media, for example Christian music videos.

Christian rock can be described as a separate genre within contemporary popular music. There are separate radio stations, record companies, record stores, music magazines, festivals, etc. - and of course artists and fans - devoted to the production, distribution and consumption of this genre of music. Moreover, it is a genre that is "Christian" not only by virtue of spreading a Christian message, but because the record companies, stores, artists, fans, etc. involved in Christian rock have other connections to institutional Christianity in addition to being involved with the music. The fans of Christian rock are (mostly) young people who are active in Christian churches ${ }^{2}$; concerts with Christian rock are arranged by, and sometimes in, churches; and there are Christian congregations that initiate their own rock groups (Howard \& Streck 1999; Romanowski 2000; Häger 2003).

\footnotetext{
1 "Rock: a language in our time" is how the Swedish title of Lawhead's "Rock reconsidered" would translate in English, and the title also covers the central argument of the book (and of other similar books, e.g., Thompson 2000).

${ }^{2}$ According to a survey quoted by Howard \& Streck $(1999,44), 90 \%$ of the people who bought records in American Christian bookshops in 1997 visited church at least four times per month.
} 
This institutional framework is a fundamental part of the definition of the concept of Christian rock: it is a genre of rock music produced, distributed and consumed within institutional Christianity. Another aspect of Christian rock, and one that is more emphasized within the Christian rock community, is the Christian content. I will not claim that this aspect is unimportant, but I do claim that a Christian message is not a sufficient criterion for placing a rock record within the genre of Christian rock. Neither, of course, is the use of biblical references or Christian symbols. In other words, artists such as Sinéad O'Connor singing "Kyrie Eleison”, or Madonna wearing a cross, are not part of what I would call Christian rock, because of the absence of institutional anchoring. ${ }^{3}$

The definitional discussion here serves several purposes. It provides part of the context for the article, and it helps to delimit the material studied. But it is also a fundamental starting point for describing the aim of the study. I will look at and discuss some videos that are at the outset defined as "Christian", as belonging to the genre of Christian rock. I will not try to see whether the studied videos are Christian or not, but I take the label "Christian" as already applied and in that sense given. The question asked in this article is rather how this quality may show in the videos, or how Christianity is visually represented in the videos on Wow hits 2002.

One central aspect of Christian rock is its character of belonging to two worlds, as it were: it is part of Christianity and part of rock music. This character of being Christian as well as rock is also a central starting point for the analysis. The two "worlds", Christianity and rock, can be seen as two repertoires or discourses from which an individual work of Christian rock, such as a music video, may draw. It is also implicit in the genre that the music draws on rock and the lyrics (at least primarily) on Christianity - although neither of these implicit assumptions necessarily appears very

\footnotetext{
${ }^{3}$ Sinéad O'Connor may serve as an example that the lines of course are never this clear-cut: she is an ordained priest, and therefore has a strong connection to institutional Christianity. However, her work as a pop artist is conducted within the mainstream popular (and folk) music business, and her following is by no means restricted to devout Christians (and even less to devout members of the church where she serves as a priest, which would be a parallel to many artists within Christian rock). For more on O'Connor, see Häger (2005).
} 
clear-cut on a closer examination. When it comes to the visual aspects of Christian rock, in a medium such as the music video, even on a superficial level there are no easy assumptions regarding repertoires. It is however clear that the medium of the music video - or the "rock video" - has become an integral part of the popular music scene during the last two decades, and therefore also part of the Christian rock scene. As Christian rock adapts in different ways to the musical forms of secular rock, it also by definition borrows its visual style at least in part from secular music videos. To partly anticipate the analysis, it may be stated that this is also the case when it comes to the Wow hits 2002 collection studied here - the similarities between these videos and mainstream videos are, at least on first view, more striking than the differences. Then the question remains: are there any particular visual elements in Christian music videos that may be interpreted as representations of Christianity?

\section{Material and Methods}

The primary material analysed here is a video collection called Wow hits 2002: the year's top Christian music videos. It is a collection of 18 videos by 18 different artists, included in a series of CDs and video tapes branded "Wow", also including titles such as Wow Worship and Wow Gospel (WOWHits.com). The series is distributed by three of the world's largest Christian record companies, e.g., Word Records. ${ }^{4}$ A more detailed description of the tape is given in an appendix. The collection was selected for material based on an assumption that it provides a cross-section of the mainstream of contemporary Christian music.

The discussion of Christian rock in the previous part of this article centred on this phenomenon as a genre of popular music. However, it is quite clear that the material analysed here is not merely or even primarily

\footnotetext{
${ }^{4}$ There are 18 videos included on the European VHS tape that is my source. According to the Wow homepage WOWHits.com, the American VHS tape also includes "Jesus Freak" by dc Talk, and the DVD two additional "classic" (as they are labelled) videos. I will not include these older videos in my material, but comment briefly on one of the three videos which I have seen, "Jesus Freak", as it provides an interesting point of comparison.
} 
"music" in any traditional sense. A music video is a visual object. It is also a very complicated form. It is not only one image but many; it is not only image but also sound; and the sound consists of both music and words. The complexity of the material of course affects the analysis. The issues of possible relevance to an analysis of a material such as music videos are far too many and too complicated to sort out in this short text. I will therefore only attempt to outline the approach used here. ${ }^{5}$

The analysis focuses on the visual elements and how these can be seen as representations of Christianity. The discussion of music is limited to some brief descriptions of style. The lyrics are primarily discussed in the instances when it is thought that the images are textually anchored - i.e. when the lyrics provide a "preferred reading" of the images (cf. Barthes 1977, 39-41). The analysis focuses mainly on single frames, or, in practice, brief shots. Larger possible units, ranging from sequences of shots, or (the equivalent of) scenes, to whole videos and the entire collection as a flow of musical videos, are discussed only as providing references to the analysis of individual images. The narrative dimension, how the images are used to tell a story, is discussed in relation to one of the videos.

The narrative aspect could provide much more information than the brief analysis here can show. But even a single photographic image, such as a frozen frame of a music video, can as a whole provide an amount of information that defies very close analysis, or at least renders such analysis too cumbersome to be practical. One further delimitation of analysis therefore involves the exclusion of many aspects of the video image, particularly aspects relating to cinematography, such as composition, lighting, etc., that are discussed to a very limited degree. What is analysed is then, to put it simply, for the most part the people and the objects appearing in front of the camera.

The analysis is inspired by semiotics, and in that tradition by Roland Barthes's (1977) discussion of the analysis of photographic images. An im-

\footnotetext{
${ }^{5}$ For a somewhat more detailed methodological discussion on the analysis of visual aspects of Christian rock, see Häger (2003).
} 
portant point in semiotics is that the meaning of a sign stems from the sign's difference from other signs. These other signs are those that are used in the rest of the studied text - the syntagm - and those signs that could be used but are left out - the paradigm. On a syntagmatic level the meaning of a particular sign used in the music videos analysed here is derived from its relation to the other signs in the particular video (and the whole collection as a text). On a paradigmatic level, the meaning of a sign is derived from its difference from signs that are not used, but perhaps are used in videos in the secular mainstream of popular music. One important aspect of the analysis in this article is therefore a comparison with secular contemporary music videos, e.g. those played on MTV.

The concept of representation is central to the discussion of the videos. The concept is borrowed from Stuart Hall (1997). A social constructionist understanding of representation is employed here. The concept of representation then above all denotes that the image or account of a certain event or phenomenon is no reflection of that which it represents but part of the construction of the object. Looking for visual representations of Christianity in Christian music videos is then a way of asking how these videos participate in the shaping of the phenomenon of Christianity in contemporary society. This question is furthermore asked in relation to another particular aspect of contemporary society, popular culture, and the discussion of the videos is a discussion of how Christianity is shaped in relation to this other - perhaps competing - entity. ${ }^{6}$

\section{Discussion of the Videos}

In this main part of the article, I will continue to discuss the videos on the Wow hits 2002 collection and elements in these videos which can be seen as visual representations of Christianity. I want to emphasize once more that the analysis is not a study of whether these videos are "Christian" or not, but an exploration into how the a priori definition - given in the title of the

\footnotetext{
${ }^{6}$ It is self-evident but should perhaps still be pointed out that the interpretations of the videos are my interpretations, and that other interpretations could be made by other viewers.
} 
video tape - of these videos as part of a Christian tradition and institutional framework may be visually conveyed in the videos themselves.

The discussion of the videos is divided into two parts. The first part deals with visual elements that directly can be attributed to a Christian tradition, such as Christian symbols and depictions of (other) practices or objects related to institutional Christianity. The second part deals with images that can be seen as referring not primarily to a Christian symbol system but rather to elements of a lifestyle - in the videos mainly expressed by the appearance of the artists - that may be connected with the form of Christianity to which Christian rock has its clearest institutional connections, American evangelical Christianity.

The main point of the analysis is to provide examples of images that may be interpreted as representations of Christianity. Since the object of study is the whole collection Wow hits 2002, the question of which image appears in which video is for the most part seen as irrelevant. In the case of reference to individual videos, the titles will be used (see Appendix). Some numerical data regarding the number of examples of a particular type of image is provided occasionally, as part of the description of this particular collection of videos, but the analysis of the videos is qualitative.

\section{Elements from Christian Tradition}

The elements from Christian tradition found in the material are divided into two types: objects and gestures. The first object to be mentioned is church buildings. In the eighteen videos on the Wow hits 2002 tape, perhaps the clearest visual connection to Christian tradition is provided by setting parts of some of the videos in and/or outside of churches. In addition to this, one video shows a sign (that is completely readable only if one pauses the tape) that reads "This area is church property". There are also interior settings that can be seen as being reminiscent of a church, but without providing enough detail or scope to allow the viewer to be certain.

"This road", which will be discussed further below, is primarily set in a church, and outside the church building. "Adore" is set partly inside a 
church, and partly in a location that in the narrative structure of the video can be interpreted as the stairs leading up to the church door. Inside the church, the artist (Jaci Velasquez) walks past stained-glass windows, on one of which the word "Holy" is readable. The singer then sings the end of the song standing in front of the altar, and the video ends with a tilt up towards the pulpit and the church organ.

Apart from the churches, only two other objects with a clear connection to Christian tradition are visible in the videos. Both appear in dc Talk's "Since I met you". One is a cross, which appears to be a grave monument. The other is a Bible, in a shot of one of the group members sitting in a chair reading the Bible and making notes or perhaps underlining passages.

The other category of visual images that can be interpreted as references to a Christian tradition in the studied video collection can be labelled gesture $^{7}$. The most obvious gestures of this kind are to be seen on the two videos that include (or in one case, "My hope is in you", entirely consists of) live material. One such gesture or pose is what could be called a typical "praise" pose: one or both arms raised, face tilted upwards and eyes closed. This gesture is also used in other videos that do not contain live material, most notably in "Begin with me", where it occurs throughout the video. Another type of gesture used is the "One way" sign, with an index finger pointing up to symbolize Jesus as the way (cf. McDannell 1995, 25, 253; Häger 2003). On "My hope is in you", the gesture is textually anchored by the lyrics "Show me your way".

As mentioned in the notes and in the appendix, another video by dc Talk, "Jesus Freak" (from 1995), is included on some issues of the Wow hits 2002 collection, but not on the European VHS tape that constitutes the material for this study. The video is accessible on the homepage of dc Talk's record company (ForeFrontRecords.com). I will not discuss "Jesus Freak" at length here, but only note that it exemplifies the use of reference to Christian tradition in an extensive way. The video includes a number of documentary

\footnotetext{
${ }^{7}$ This category is adapted from Barthes's (1977) discussion of pose. I follow Klinkmann (1999), who claims that gestures are an integral part of the visual appearance of popular music. Gestures as used at Christian rock concerts are discussed further in Häger (2003).
} 
shots, including images of an imprisoned nun and a procession with priests and members of an Orthodox church. There are several brief images showing different paintings of Christ. The shots of the band include very central Christian symbols: a dove (e.g., filling the screen at the opening of the video), bread and wine, and a cross (carried by one of the band members), as well as poses both of prayer and praise.

The "Jesus Freak" video is interesting here in the way that it shows that unmistakable visual references to a Christian tradition are possible and even used in the video of one of the biggest Christian rock hits of the 1990s. In comparison, the (newer) videos on Wow hits 2002 are visually very ambiguous and unclear - as underlined by the observation that the Christian references discussed in this part of the article, objects or gestures, can be found in six of the eighteen videos in my material. Gow (1999) found that no more than $17 \%$ of the videos aired on the Christian music channel he studied had visual references to Christianity.

Of the videos on Wow hits 2002, the one which most clearly uses images of Christianity is "This road" with the group Jars of Clay. ${ }^{8}$ The discussion of the video here relates to individual images as well as to the narrative dimension. The video consists of two intertwining parts: the main part (in sharp colour) shows the band playing in and outside a church, apparently somewhere in rural America; the other part, that can be interpreted as flashbacks, consists of monochrome, grainy "home movie" type of images, with the band members in different locations in what appears to be a large East Asian city.

The church locations show the band members performing in front of the altar inside the church, with burning candles and a cross hanging on the wall, as well as the singer sitting in a pew among churchgoers of different ages and ethnicities. The church crowd goes out of the church and sings with the band in the church yard, before finally following the band away from the camera along a narrow road. The Asian footage shows the band in

\footnotetext{
${ }^{8}$ On the video, the artist is given as "City on a hill featuring Jars of Clay". City on a hill is a cooperation between different artists that have issued a series of albums with "praise" type songs (cf. the website city on a hill).
} 
different city locations, riding rickshaws, coming out of what appears to be a Buddhist temple, etc.; and in religious meetings, singing for and praying with (while holding their hands over) members of the local community.

The church scenes, as well as the prayer scenes of the Asian footage, can be taken as clear examples of visual representations of Christianity. A more symbolic element, which features in the title of the song and as a central element in the lyrics, is the road that the band members and the church crowd start walking down at the end of the video. The road is an often used metaphor in Christian (as well as other religious) language, and the lyrics in the chorus of "This road" evoke one aspect of this:

This road that we travel

may it be the strait and narrow ${ }^{9}$

This is a reference to Matthew 7:14: "But small is the gate and narrow the road that leads to life, and only a few find it" (in the New International Version). The song lyrics apparently express a hope that the "we" who are travelling, and singing, may be among the few to find this road, and the images on the video confirm this hope. ${ }^{10}$

In the visual context of the video, the road also takes on another meaning. The two different settings used in the video, the American country church and the big Asian city, make up a contrast, emphasized by the difference in colour and grain of the footage, by the physical appearance of the people in the two settings, and details such as the Buddhist temple - a visual representation of Buddhism that I interpret as a contrast to the church(es), emphasizing the Christian elements and their opposition to the foreign and non-Christian. This contrast in settings can be seen as a depiction of a categorization of "us" and "them", where the people and culture in the Asian setting come to represent "them", or the "Other".

\footnotetext{
${ }^{9}$ The lyrics are audible on the video tape (Wow hits 2002), and can be found on the Jars of Clay Discography web site.

${ }^{10}$ The King James translation talks of a "strait" gate, rather than "small", and in the lyrics this adjective has been applied to the road instead.
} 
Such an interpretation of the video's two settings, coupled with the depictions of the evangelising activities of Jars of Clay in the Asian setting, and the people walking off at the end of the video, to my mind evokes a special aspect of the road: it is the road to the Other, to those who have not heard the gospel. Taken this way, the sum of the images on "This road" evokes a theme strongly emphasized in evangelical Christianity: the call to missionary work. This is further emphasized visually by a change in picture quality at the end of the video: as the band and the church group walk down the road, the picture changes from the sharp colour images of the American setting, to the grainy dull images of the Asian footage in the video. ${ }^{11}$

At the end of the video, a sign appears with the following dedication:

To our brothers and sisters who are persecuted and suffer for their faith... We will remember your chains. May the grace of the Lord Jesus Christ, and the love of God, and the fellowship of the Holy Spirit be with you all (Wow hits 2002).

If one assumes that the "brothers and sisters" are exemplified by the Asians shown in the video, the persecution theme brings out another aspect of how Western evangelical Christianity defines "us" and "them" - in this case Christians in "the West" and persecuted Christians in "the East". ${ }^{12}$ The last sentence further verbally anchors the video in Christian tradition: it is a Bible verse (from 2.Corinthians 13) and is traditionally used as a benediction in Christian liturgies.

\section{The Appearance of the Artists}

Despite a video such as "This road", the more or less explicit visual references to Christian tradition are not a central aspect of most of the videos

\footnotetext{
${ }^{11}$ In the very beginning of the video, in footage showing Jars of Clay sitting inside the American church, the same grainy picture quality is used. The use of this picture quality at the beginning and the end can thus also be seen as a framing of the video. Another interpretation, again associating the grainy, monochrome pictures with Asia, would be that Jars of Clay are just returning from the visit from which pictures are shown in the video, and are now inspiring their fellow Americans to join in the missionary work.

${ }^{12}$ This type of "othering", particularly when using a phrase such as "our brothers and sisters", can also be interpreted as an expression of solidarity.
} 
on Wow hits 2002. In this part of the article, I will discuss another side of the videos, and one that also could be interpreted as a set of visual representations of Christianity. This concerns the appearance of the artists. The artists are often a central part of the visual content of a music video, and artists with a favourable appearance are arguably a central reason for the success of the whole concept of the music video. This can also be seen in the videos on Wow hits 2002. In all of the 18 videos, the performing artists play the main part, and in several videos they are the only people shown. How these artists look is then a central aspect of the videos.

In videos playing on secular music channels such as MTV, an important part of the visual impact of the videos is often the rather scarce attire of the artists. In contrast to this, a striking feature of the videos on Wow hits 2002 is the relatively speaking proper dress of the artists. The degree of "decency" of the artists on Wow hits 2002, and the relation of this to the videos' declared character of being Christian, will be discussed in this part of the article.

A discussion of what is decent or proper or moral clothing is by definition an issue very much influenced by subjective or culturally learned values. This is true for the producers and viewers of these videos, and also for me as a viewer with an intent to analyse and discuss the videos within an academic context. Even though I begin the discussion on the appearance of the artists on Wow hits 2002 with a description that focuses on "facts" such as skirt length, other descriptive elements are still left out and deemed unimportant, e.g., the colour of the clothes, which another viewer might have included in the description.

The videos on Wow hits 2002 feature both male and female artists. There are six female solo artists and one all female group. All of these performers wear skirts or dresses as at least one of their outfits, and none of them wears a skirt that ends above the knees. Most skirts end just above the ankles, or are full length. On the whole tape, there are two exceptions to this rule established by the all-female acts. The female singer of the group Benjamin Gate wears a coat that ends just above the knees and is visible, in long shots, in the beginning and end of their video. ${ }^{13}$ The video "Hey, hey" does not

\footnotetext{
${ }^{13}$ It may be noted that Benjamin Gate is one of the non-American groups on the collection: they are from South Africa.
} 
feature female artists, but begins with a few shots of a group of cheerleaders, wearing traditional cheerleader attire, including the short skirts. No female artist on Wow hits 2002 wears what I would see and describe as low-necked dresses or tops or any tops that do not cover their abdomen. Quite a few wear sleeveless tops and there are among the outfits a few dresses that could be described as evening-gowns, including some with bare shoulders.

The male artists are also dressed in what could be described as a decent fashion. There is one typical boy band featured on the tape, Plus One. Their video "God is in this place" is set entirely on a sandy beach, where the boys dance, play football and run around in the water. The young men in the video are however not dressed for swimming: they all wear shirts and trousers. One member of the group wears his long-sleeved shirt unbuttoned for part of the video, and a few of them wear half-long trousers or knickerbockers. In the whole collection, there are two male artists who wear shorts: one of the members of Jars of Clay, as the band performs in the American setting of their video; and a member of dc Talk, in a brief shot (among several in their video showing sports activities) from a golf course.

In comparison to many videos playing on MTV, the clothes style on the videos on Wow hits 2002 can then be described as quite proper. I do not have access to any information regarding the existence of an official dress code in the Christian music industry, although it seems quite likely that some set of rules would be applied. The appearance and dress of Christian rock artists is a however a topic in the Christian music press. Some of the most ardent critics of Christian rock (e.g., Godwin 1990; Arnroth 1993) discuss the issue, often focusing on long hair on men. Arnroth $(1993,79)$ states that the appearance of the artists is a "gigantic problem in the world of Christian rock" exemplified by "tight leather pants, torn jeans [and] outfits that hardly speak of purity and virtue".

The issue of appearance and clothing is discussed from a different perspective by one of the groups in the Wow hits 2002 collection. The lyrics of "Barlow girls" with Superchic(k) talks of girls' appearance, promoting modest dress: 
dress to impress, can be oh so tempting you can get noticed with your body

and concludes that "you might" but "you shouldn' $t$ ". ${ }^{14}$ The members of Superchic(k) also discuss the matter of their own appearance as Christian artists in interviews. In an interview in the leading Christian rock magazine CCM Magazine ${ }^{15}$ they criticize Britney Spears for "cavorting in sexually suggestive outfits while performing sexually suggestive routines", and are presented as an alternative to this popular female artist. ${ }^{16}$ The text even calls the lead singer Tricia "anti-Britney", and continues that both of the female band members "manage to stay trendy and accessorize their outfits without exposing skin". "It's about not making guys lust", guitarist Melissa explains.

By discussing the clothing of both male and female artists in this article, I obviously attempt to achieve some sort of gender balance. But it is also clear that the issue of appearance and being "sexually suggestive" is anything but gender-neutral, and the statements of Superchic(k) could be discussed from a perspective inspired by feminism. As quoted above, the girls in Superchic(k) explicitly say that they do not wear anything that can be seen as too sexually enticing and that they do this out of respect for their male fans. It is the interests and needs of the men that are seen as important, and not whether the girls themselves want or do not want to "expose skin" or "dress to impress". But one could on the other hand of course also see the attempt to explain to teenage girls that they do not have to try to look like Britney Spears as an act of emancipation.

It seems that short skirts, cleavage or bare stomachs are excluded from the visual content of the Christian videos studied here, and the videos are quite different from many secular counterparts when it comes to content

\footnotetext{
${ }^{14}$ Lyrics on Superchic(k) Unofficial Site and Wow hits 2002. The song has apparently been inspiring, since there is a web site, for girls who "Dress Modestly, Commit to Abstinence Until Marriage, Save Their Hearts for Their Future Husbands", using the song title in its name (Barlowgirl.net).

${ }^{15}$ I have accessed the interview on CCMMagazine.com.

${ }^{16}$ Britney Spears is also easy to use as an explicit point of comparison of CCM videos with mainstream videos. Her attire and also her dancing exemplify a style that seems to be off limits for the CCM videos. See for example "I'm a slave $4 \mathrm{u}$ " and "Don't let me be the last to know" (available on VH1.com: Britney Spears).
} 
that can be interpreted as overtly sexual. But there are still elements in these videos that can be seen as ambiguous in that respect, both regarding artists' attire and action. The lead singer of Superchic(k) sings that girls should not (have to) "dress to impress", but in the video, she appears in tight leather or latex trousers and a tight sleeveless top, and with heavy make up. Similar attire is worn by other artists in the collection.

There are also poses and gestures that can be seen as ambiguous with respect to their sexual implications. This is perhaps the topic of discussion in this article where the subjective or cultural opinions of the viewer play the greatest part. Some would perhaps see the dance moves of Plus One or Jump $5^{17}$ as sexually suggestive, and others would notice the movements and glances of Jaci Velasquez. I will here discuss two examples of such ambiguity which I find interesting.

The first example is made up of two brief shots from Superchic(k)'s "Barlow Girl", where the lead singer - dressed as previously described - walks towards the camera, and (in the second shot) stops, puts her hands on her hips and begins to turn around, copying the typical movement of a model on the catwalk. In - perhaps ironically - mimicking a photo model, the singer puts herself in the place of a person whose role very much is to be looked at and admired for her looks, and invites the viewers of the video to see her as a photo model and someone who is desired for her good looks. This produces ambiguity and perhaps even a contradiction between the lyrics and the video.

The second example that I will mention also concerns the relation between lyrics and image. The ambiguity that interests me here is quite often present already in the lyrics of many Christian pop songs and involves the question of the addressee. If a Christian artist sings "You're more than what I wanted" or "I will give you everything" (to use two examples from the collection studied here), to whom is the text addressed, to God or to a human being? In a video, one answer can be provided by the artist's gaze:

\footnotetext{
${ }^{17}$ Jump 5 consist of five teenagers, three girls and two boys, performing in the vein of Ateens or S Club 7.
} 
if an artist looks into the camera while singing, an interpretation based on television convention would be that the viewer of the video is the text's addressee. On Wow hits 2002, there are several examples of how this convention however only increases the ambiguity, when the lyrics apparently are directed to God but the artists look into the camera singing them.

Jump5 sing in the chorus of "Spinnin' around":

I keep my heart, my eyes, on you, cause you keep me spinning around ${ }^{18}$

Reading the lyrics and knowing that the group is part of the genre of Christian rock, I would see God as the addressee, and interpret the lyrics as saying that God is the one who sustains the person who makes this statement. But viewing the video, where the members of Jump5 not only look but also point with their fingers into the camera delivering the line, it seems that the viewers of the video, or the fans of the group, are the ones who keep Jump5 going.

The lyrics of "Begin with me", with Point of Grace, are clearly a prayer:

Begin with me

Come and renew my mind

And lead me to the light

'Til I am more like You Jesus ${ }^{19}$

A video viewer who does not concentrate on these lyrics, but just notices an artist in a music video smiling into the camera singing "begin with me", will most likely not interpret the song and the context as a prayer, but perhaps rather as some kind of invitation. Depending on interpretation, it is possible to claim that the sexual content central to many mainstream music videos is not absent from a video such as "Begin with me" - in spite of the long

${ }^{18}$ Lyrics on Jump5 Lyrics, and Wow hits 2002.

${ }^{19}$ Lyrics on Point of Grace, and Wow hits 2002. 
skirts and restrained choreography. At the very least, the video, and other videos on Wow hits 2002, contains ambiguities in relation to the depictions of sexuality or sensuality.

As was stated above, an opinion on the degree and meaning of sensualism in a visual medium is very much a matter of subjective perception and cultural background. To the extent that I see sensualism as part of the rock repertoire, and decency as part of the Christian repertoire, it becomes obvious that I am not able to see sensualism as part of a Christian repertoire, or sensuality as part of a representation of Christianity. This apparent inability may be understood as caused by my own Protestant background, and seen as a reminder that the interpretation of such a complex text as a music video is always dependent on the cultural baggage of the interpreter..$^{20}$

Most Christian rock is also produced and performed by Protestants. It can then be understood that the background of the producers causes them to exclude sensuality as a visual representation of Christianity. So if it seems quite clear that there is much less obvious sexual content in these videos than e.g., in videos on MTV, this relative modesty can be seen, specifically because of the American Protestant context, as a representation of one particular form of Christianity.

\section{Concluding Remarks}

The starting point for the discussion in this article is a word in the title of the video tape that has been used as data: the word "Christian". If the Wow hits 2002 collection contains not merely music videos, but Christian music videos, how is this visible in the actual videos? One answer is that, at least at the outset, it is often rather invisible, since most of the videos look very much like any contemporary music videos. But the analysis here suggests two possible types of visual representations of Christianity in the Wow hits 2002 videos: visual references to Christian tradition; and a style and appearance of the artists that is much less overtly sexual than many mainstream music videos.

\footnotetext{
${ }^{20}$ As a contrast, see the discussion on the appearance of the pop star Madonna by Catholic priest and sociologist, Andrew Greeley $(1988,165)$.
} 
References to Christian tradition are not used very extensively, but were still quite clear in some videos, not least in those set in a church. There are also images not discussed here which could be interpreted as rather ambiguous religious symbols, e.g., a conspicuous use of lighting effects. The narrative of some of the videos could also be interpreted as references to Christian tradition, as there are for example a few stories that could be seen as conversion narratives (notably in Rebecca St. James's "Reborn").

It seems to me quite clear that the videos on Wow hits 2002 are, in comparison to mainstream pop videos, quite "decent" when it comes to the way the artists dress; but, on the other hand, there is room for a noticeable sensualism. This is more evident in some videos than others. One interpretation of this is that there are evidently certain - rather well defined - boundaries for what is accepted appearance and action in a(n American) Christian music video, but that the artists and the producers of these videos try to use all possibilities within these limits, and perhaps even try to stretch the boundaries somewhat.

However that may be, the tension between decency and sensualism is part of the ambiguity of these videos. This ambiguity can be seen as a central aspect of the appeal and efficiency of music videos: they leave room for interpretation and thus encourage repeated viewing. It is even possible to suggest that Christian music videos may want to be particularly ambiguous and leave special room for interpretation, since their viewers must be allowed to see them both - at least initially - as music videos, attractive and interesting as such, and as conveyers of a Christian message. The lack of clear Christian visual references in a majority of the videos - and in similar material studied by Reid \& Dominick (1994) and Gow (1999) - supports such an assumption, since such references could be seen as reducing the ambiguity.

As previously stated, I see Christian rock as an arena where institutional Christianity is negotiating its boundaries with contemporary society and culture. Using the expressions of popular music, including music videos, is a form of accommodation to contemporary society, but producing a particular 
Christian version of it, in order, for example, to provide entertainment for Christian youth (Howard \& Streck 1999), constitutes an attempt to resist the influence of the contemporary, "secular" culture in the form of mainstream popular music. Christian rock can be seen as an accommodation to the (musical) form of popular music, but a resistance towards its (lyrical) content. As for the visual aspects of the videos, they clearly represent an attempt to accommodate to the form of music video when it comes to editing, for example; while what here has been described as a relative decency in attire in the (American) Christian music videos can be seen as an example of resistance towards contemporary culture as expressed for example in many videos on MTV.

Instead of searching for representations of Christianity in the videos, as I have done in this study, it would also be possible to understand the videos as a whole as visual representations of Christianity. The label "Christian" attached to the studied music video collection would then be understood as defining everything on the videos as part of Christianity. Not only the churches, conservative styles of dress and perhaps a few other details are Christian, but perhaps everything showing on the videos would be seen as representations of Christianity. The videos would then provide visual - and the lyrics textual and the music musical - clues to what the term "Christian" means in contemporary culture. As a point of departure for analysis, this perspective does not seem fruitful, since it provides no hints at where to start the discussion. There would be no way of deciding which images were relevant for analysis of the visual appearance of Christianity, and the meaning of the label Christian would necessarily become very vague. On the other hand, this may be interpreted as an important insight: that the contemporary meaning of the concept of Christianity, and the place of Christianity in today's culture and society, is very vague, and that the phenomenon of Christian rock is an example of this. 
Bibliography

\section{Arnroth, Thomas}

1993 Hur den kristna rocken spelade ut sin roll. Uppsala: Magazinet.

\section{Barthes, Roland}

1977 Image - Music-Text. Glasgow: Fontana.

\section{Berger, Peter}

1967 The Social Reality of Religion. London: Faber.

Godwin, Jeff

1990 What's Wrong with Christian Rock? Chino: Chick Publications.

Gow, Joe

1999 Rockin', Rappin', and Religion: Programming Strategy on Z Music Television. - Popular Music and Society, Summer 1999. [http: //www.findarticles.com/p/articles/mi_m2822/is_2_23/ai_61837437; 29.10.2004.]

\section{Greeley, Andrew}

1988 God in Popular Culture. Chicago: Thomas More.

\section{Häger, Andreas}

2003 Christian rock concerts as a meeting between religion and popular culture. - Tore Ahlbäck \& Björn Dahla (eds), Ritualistics. Based on Papers Read at the Symposium on Ritualistics Held at Abo, Finland, on the July 31-August 2, 2002, 36-55. Åbo: Donnerska Institutet.

2005 Under the Shadow of the Almighty: Fan Reception of Some Religious Aspects in the Work and Career of the Irish Popular Musician Sinéad O'Connor. - Michael Gilmour (ed.), Call Me the Seeker: Listening to Religion in Popular Music, 215-225. New York: Continuum.

\section{Hall, Stuart (ed.)}

1997 Representation: Cultural Representations and Signifying Practices. London: Sage.

\section{Howard, Jay R. \& John M. Streck}

1999 Apostles of Rock: The Splintered World of Contemporary Christian Music. Lexington: The University Press of Kentucky.

\section{Klinkmann, Sven-Erik}

1999 Elvis Presley: Den karnevalistiske kungen. Åbo: Åbo Akademi University Press.

\section{Lawhead, Steve}

1982 Rock: ett språk $i$ vår tid. Örebro: Libris. 


\section{McDannell, Colleen}

1995 Material Christianity. Religion and Popular Culture in America. New Haven: Yale University Press.

Reid, John E. \& Joseph R. Dominick

1994 A Comparative Analysis of Christian and Mainstream Rock Music Videos. - Popular Music and Society 18(2), 87-97.

Romanowski, William D.

2000 Evangelicals and Popular Music: The Contemporary Christian Music Industry. - Bruce David Forbes \& Jeffrey H. Mahan (eds), Religion and Popular Culture in America, 105-124. Berkeley: University of California Press.

Thompson, John J.

2000 Raised by Wolves: The Story of Christian Rock \& Roll. Toronto: ECW Press.

Audiovisual

Wow hits 2002: the year's top Christian music videos. EMI Christian music group/Word Entertainment/Provident music group. 2001. [VHS video tape]

Web pages

Barlowgirl.net. http://www.barlowgirl.net [29.10.2004].

CCMMagazine.com http://www.ccmmagazine.com/features/fullstory_ cont2.asp?Id=2147 [29.10.2004].

city on a hill http://www.city-on-a-hill.com [29.10.2004].

ForeFrontRecords.com http://www.forefrontrecords.com [29.10.2004].

Jars of Clay Discography http://www.jarchives.com/discography.htm [29.10.2004].

Jump5 Lyrics http://www.elyrics.net/go/j/Jump5/Spinnin'_Around/ [29.10.2004].

Point of Grace http://www.pointofgrace.net/index.php?content=musicfree [29.10.2004].

Superchic(k) Unofficial Site http://www.superchick.4t.com [29.10.2004]. 
VH1.com: Britney Spears. http://www.vh1.com/artists/az/spears_britney/ videos.jhtml [19.1.2006].

WOWhits.com http://www.wow2005.com [29.10.2004].

Appendix: Description of the video collection called Wow hits 2002: the year's top Christian music videos.

The collection contains 18 music videos by 18 different artists. The titles and artists, in order of appearance on the tape, are:

Song title

Live out loud

Everything

Call on Jesus

Spinnin' around

Begin with me

God is in this place

More than what I wanted

Adore

My hope is in you (live)

Reborn

This road
Artist

Steven Curtis Chapman

Stacie Orrico

Nicole C. Mullen

Jump5

Point of Grace

Plus One

CeCe Winans

Jaci Velasquez

Third Day

Rebecca St. James

City on a Hill (featuring Jars of Clay)

Since I met you (live)dc Talk

You already take me there

Switchfoot

Jaded

Larue

Hey, hey

The Elms

Power in your hands Paige

Barlow girls

Superchic(k)

All over me

Benjamin Gate 
According to WOWHits.com, the American version of the collection also features a 19th video under the heading of "classic". This video is "Jesus Freak" with dc Talk. The following text on the tape cover describes the collection:

The Wow hits 2002 video features today's best new videos from Christian music's top artists. Each year, Wow brings together the "best-of-the-best" to create the definite collection of today's music video hits. Wow hits 2002 - the video is a "must-have" for any music collection. It is the best way to own your favorite music video hits and the perfect introduction to new favorites you haven't yet discovered. Wow has a new look! Be sure to look for Wow's new design on all new Wow products. Wow. It's everywhere.

(Wow hits 2002; back cover; the italics represent text coloured on the original)

Each video on the tape is preceded and followed by a text giving the title of the song, the name of the artist, the record company and homepage.

The title of the tape can be taken to indicate that it includes the best videos of 2002, but the production year of the tape is given as 2001, and most of the videos are from 2000 or 2001 (a few are older). 